\title{
Characterization of Glass Alterations in Ancient Glass from Various Environments from Broborg, a Vitrified Swedish Hillfort
}

\author{
Bethany Matthews ${ }^{1}$, Bruce Arey ${ }^{1}$, Carolyn Pearce ${ }^{1}$ and Albert Kruger ${ }^{2}$ \\ ${ }^{1}$ Pacific Northwest National Laboratory, Richland, Washington, United States, ${ }^{2}$ US DOE Office of River \\ Protection, Richland, Washington, United States
}

Glass is considered a highly durable material as evidenced by our continued use of it as vessels for liquid such as dishware and vases. Since both natural and manmade glasses have been around for millennia, there are many case studies that probe the effects of aging, weathering, and wear on glass. These studies demonstrate that glass is resistant to wear, making it a suitable candidate for encapsulating waste, such as radioactive material, that would post a threat to the environment [1,2]. The composition of the glass affects weathering behavior, and alteration rates change over the course of decades due to changes in the altering environment. The effects of these external influences make it is difficult to study and compare alteration of different types and ages of glasses. For glass scientists to understand how a synthetic glass might alter and corrode in a certain environment, it is important to know the dominant mechanisms of alteration and alteration features they produce on the glass.

Glass from Broborg, a 1500-year-old vitrified hillfort in Sweden, is considered as an analogue to study the long-term effects of aging on waste glass, which will be used to immobilize hazardous and chemical waste at the Hanford Site, Washington. The chemical compositions of the two glasses are comparable, and the near-surface weathering environment at Broborg is similar to that of the proposed disposal facility [3]. Glassy samples were excavated from the wall at Broborg and examined for alteration features using a sample preparation and handling method described in [3]. Two dominate glass phases were identified throughout the wall and were distinguished as 'dark glass' and 'clear glass.' To distinguish the effects of different environments on the two different glass types, samples pulled from the outer wall are interrogated and compared to samples from the inner wall. Samples from the outer wall were in contact with the topsoil where the glass is exposed to the full effects of the environment. Samples from the inner wall are more sheltered from water and microbes. Here we present different corrosion features characteristic of two different glass phases (dark and clear) exposed to these two environments: the top-soil layer and an inner wall.

Due to its capability for site-selective sampling while viewing in the microscope, a dual-beam focused ion beam scanning electron microscope (FIB-SEM) is used for specimen preparation for scanning transmission electron microscopy (STEM) analysis. This is feature is essential when attempting to prepare specimen from samples which have a large range of heterogeneity or a varied topography and is particularly valuable when preserving sensitive features which are of interest for corrosion analysis, such as cracks where water might sit longer and accelerate alterations. SEM imaging is used to explore the topology and to select regions of interest. To interrogate the chemical composition and morphology below the surface of selected regions, STEM energy dispersive x-ray spectroscopy (EDS) and imaging is employed. The two glass types exhibit a variety of corrosion features both at the surface and up to tens of microns below the surface. Figure la shows one sample, wherein FIB samples removed from the bulk show layering in the sample (b and d), inclusions (e), and phases separation (c and f). In addition to these corrosion features, microscopic characterization of the glass samples from Broborg has also provided information on the materials and methods used for vitrification by the Iron Age people. 

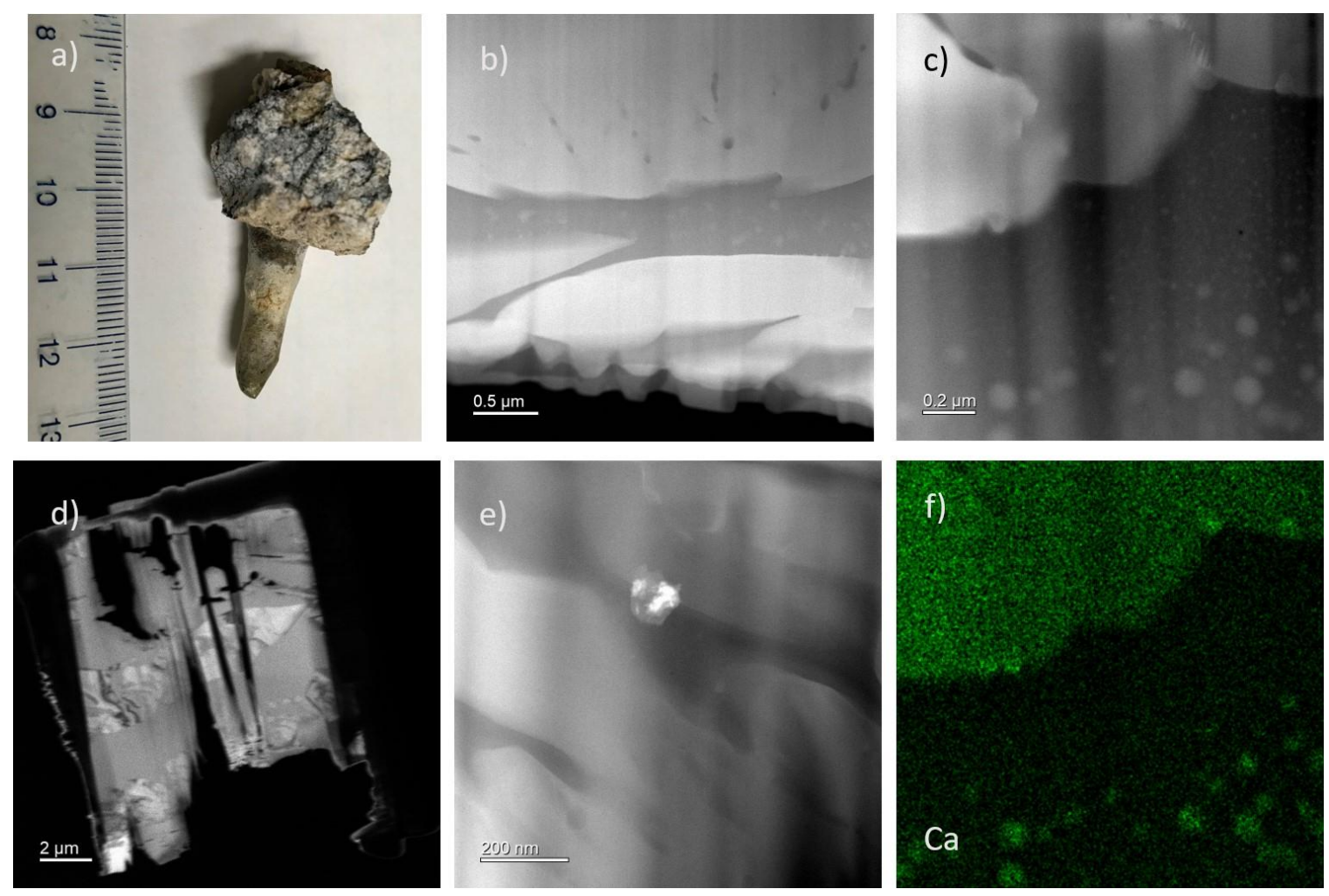

Figure 1. a) A sample containing dark glass from the inner part of the wall. a)-e) are HAADF STEM images of FIB samples pulled from the sample in a). f) shows the elemental map of Ca corresponding to c), showing the spheroid deposits are rich in Ca compared to the surrounding glass.

\section{References}

[1] Weaver et al., American Ceramic Society Bulletin, Vol. 95, No. 4

[2]Ojovan, M. I. and Lee, W.E. (2005) An Introduction to Nuclear Waste Immobilisation, Elsevier, Amsterdam

[3] J. L. Weaver, et al., International Journal of Applied Glass Science (2018) p. 1 